Н. В. Коновалова, Н. И. Храменко, Е. В. Иваницкая, Т. М. Серебрина, А. В. Рыбалко ГУ “Институт глазных болезней и тканевой терапии им. В. П. Филатова НАМН Украины” - е. Одесса, Украина

\title{
РОЛЬ ЭЛЕКТРОФОРЕЗА ПРОТИВОВОСПАЛИТЕЛЬНЫХ СРЕДСТВ В ЛЕЧЕНИИ УВЕИТОВ
}

Социальная значимость увеитов определяется высокой частотой встречаемости, преимущественным поражением лиц трудоспособного возраста, высокой частотой инвалидизации по зрению. В последнее время количество данной патологии значительно увеличилось.

Цель работы - изучить терапевтическую эффективность электрофореза Ципронекса ${ }^{\circledR}$ и Дексаметазона ВФЗ в комплексной терапии больных увеитами (передними и задними).

Материалы и методы. Под нашим наблюдением находились 67 пациентов (67 глаз), рандомизированных на 2 группы: 1-я группа больных (30 человек) получала системную противовоспалительную, иммуносупрессивную терапию, а пациентам 2-й группы (37 человек) был применен трансорбитальный и эндоназальный электрофорез Ципронекса ${ }^{\circledR}$ и Дексаметазона ВФЗ. Обследование: проверка остроты зрения, поля зрения, тонометрия, биомикроскопия, офтальмоскопия. Срок наблюдения - 3 месяца.

Результаты и их обсуждение. Полученные данные свидетельствуют об эффективном использовании в комплексном лечении увеитов электрофореза Ципронекса ${ }^{\circledR}$ и Дексаметазона ВФЗ независимо от этиологии процесса. Уменьшение толщины сенсорной части сетчатки наиболее выражено в группе с использованием электрофореза Ципронекса® и Дексаметазона ВФЗ в зоне фовеа - на $35,8-45,6 \%$ ( $=0,0001)$, что клинически выражается в уменьшении кистозного и диффузного макулярного отека и повышении остроты зрения. При очаговом и диссеминированном хориоретините (заднем увеите) в период ремиссии показатели толщины сенсорной части сетчатки в области фовеа уменьшились на 38,5 \% ( $=0,001)$, что связано с остатками диффузного отека, возникновением вторичного дистрофического процесса в сетчатке в результате воспаления.

Выводы. 1. Электрофорез Ципронекса ${ }^{\circledR}$ и Дексаметазона ВФЗ у больных увеитами независимо от этиологии процесса способствует исчезновению признаков воспаления, стабилизации зрительных функций, повышению остроты зрения в 3,5 раза и расширению поля зрения. 2. Электрофорез Ципронекса ${ }^{\circledR}$ и Дексаметазона ВФЗ хорошо переносится больными и может быть использован в лечении увеитов независимо от этиологии.

Ключевые слова: увеиты, ОКТ, электрофорез, Ципронекс®, Дексаметазон ВФЗ.

Увеиты являются актуальной проблемой практической офтальмологии в связи с их широкой распространенностью, хроническим рецидивирующим течением, развитием многочисленных осложнений $[1,4,7]$. При переохлаждении, нарушениях обмена веществ, иммунитета и аутоиммунных процессах сосудистая оболочка глаза часто вовлекается в воспалительный процесс. Преимущественно возникает поражение лиц молодого, трудоспособного возраста. Инвалидизация и временная нетрудоспособность при длительном течении и рецидивах заболевания определяет высокую социальную значимость проблемы $[1,5]$. В общей структуре заболеваний глаз увеиты составляют 7-30 \% и в 5-18 \% случаев являются причиной слепоты [4]. Одним из наиболее распространенных осложнений увеитов является макулярный отек, который становится частой причиной как об- ратимого, так и стойкого снижения остроты зрения. Разрушение цитокинами гематоретинального барьера ведет к просачиванию жидкости в межклеточное пространство, где она накапливается в наружном плексиформном и внутреннем ядерном слоях вокруг фовеа. Это заметно на снимках оптической когерентной томографии (ОСТ) в виде увеличения толщины сетчатки как проявление воспалительного процесса. Так как толщина сетчатки в большей степени коррелирует с остротой зрения, для оценки объективной динамики течения заболевания используются снимки ОКТ $[3,6,7,8]$. Персистирующий макулярный отек может приводить к необратимому разрушению связей между нейронами сетчатки, развитию глиоза или атрофии, что заканчивается стойкой потерей зрения. В то же время транзиторный отек макулы часто разрешается благоприятно, а острота зрения восстанавли- 
вается $[9,10]$. Обычно для лечения увеита назначают местные инъекции стероидов (периокулярные или интравитреальные). Однако некоторым пациентам, страдающим увеитом или панувеитом, может потребоваться длительная иммуносупрессивная и противовоспалительная терапия в виде системного применения кортикостероидов $[9,10]$. Альтернативой этой терапии может служить введение методом электрофореза Ципронекса ${ }^{\circledR}$ и Дексаметазона ВФЗ. Дексаметазон оказывает противовоспалительное, антиаллергическое и иммуносупрессивное действие, влияет на все фазы воспалительного процесса, уменьшает проницаемость сосудов, угнетает миграцию лейкоцитов, фагоцитоз, высвобождает кинины и способствует образованию антител [10]. Ципронекс $®$ - антибиотик из класса фторхинолонов, обладает бактерицидным действием, влияет на синтез ДНК бактерий, что реализуется благодаря угнетению ДНК гиразы, демонстрирует высокую эффективность по отношению к основным возбудителям бактериальных инфекций. Препарат обладает высокой антибактериальной активностью, низкой частотой резистентности основных возбудителей увеитов.

Цель работы - изучить терапевтическую эффективность электрофореза Ципронекса ${ }^{\circledR}$ и Дексаметазона ВФЗ в комплексной терапии больных увеитами (передними и задними).

Материалы и методы. Под наблюдением в отделении воспалительной патологии глаз ГУ “Институт глазных болезней и тканевой терапии им. В.П. Филатова НАМН Украины" находились 67 пациентов от 18 до 62 лет с диагнозом увеит (передний и задний) различной этиологии, средний возраст которых составил $31,2 \pm 15,7$ лет, среди них женщин было 25 (37,3 \%), мужчин - 42 (62,6 \%). Исследовались: острота зрения, поле зрения, внутриглазное давление, ОКТ, биомикроскопия, офтальмоскопия. О наличии макулярного отека можно было судить в случае увеличения толщины сетчатки в фовеа более $230 \mu \mathrm{m}$. Пациенты были рандомизированы на 2 группы: 1-я группа больных (30 человек) получала системную противовоспалительную, иммуносупрессивную терапию, а пациентам 2-й груnпь (37 человек) был применен электрофорез Ципронекса ${ }^{\circledR}$ и Дексаметазона ВФЗ. Трансорбитальный электрофорез: активный электрод - в виде ванночки, добавляли 2-3 мл $2 \%$ раствора хлористого кальция, 1,0 мл Ципронекса ${ }^{\circ}, 1,0$ мл Дексаметазона ВФ3). Анод позитивный. Сила тока постепенно возрастала от 0,3-0,5-0,8 mА до $1 \mathrm{~mA} ; 3$ мин. - 5 мин.- $8-10$ мин. Индиферентный электрод с гидрофильной прокладкой находился в воротниковой зоне. Эндоназальный электрофорез: активный электрод в виде носовой турунды (1,0 мл Ципронекса ${ }^{\circledR}, 1,0$ мл Дексаметазона ВФЗ). Анод позитивный. Сила тока возрастала от
0,3-0,5-0,8 mA до $1 \mathrm{~mA} ; 3$ мин.- 5 мин.- 10 мин. Срок наблюдения - 3 месяца.

Статистическую обработку полученных данных проводили с помощью программы Statistica 7.0, используя параметрический критерий Стьюдента для попарного сравнения обеих групп и предварительной оценки нормальности распределения, критерия Крускалла-Уоллиса в случае одномоментного сравнения более двух групп, а также критерия ранговой корреляции Спирмена [2].

Результаты и их обсуждение. Под влиянием проведеного лечения стихание признаков воспаления наблюдалось к 4-5 суткам от начала лечения. Так как сроки наблюдения за пациентами составили 3 месяца, нами представлены результаты, полученные по истечении этого срока в сравнении с исходными. Данные динамики остроты зрения и полей зрения, полученные в результате наблюдения, представлены в табл. 1.

В результате проведенного лечения наблюдалась не только стабилизация зрительных функций, но и их повышение в обеих группах. Острота зрения достоверно повысилась в 3,5 раза в группе с применением электрофореза Ципронекса ${ }^{\circledR}$ и Дексаметазона ВФЗ в результате резорбции макулярного отека.

У большинства пациентов с передними и задними увеитами были диагностированы изменения показателей толщины сенсорной части сетчатки. При изучении морфометрических показателей по данным ОКТ в различных зонах глазного дна в группе пациентов, получавших противовоспалительную и иммуносупрессивную терапию без электрофореза (срок наблюдения 3 месяца), были определены следующие значения (табл. 2).

Анализ данных, представленных в табл. 1, показал, что под влиянием лечения при переднем увеите средняя толщина сенсорной части сетчатки в фовеолярной зоне - уменьшилась с $295,2 \mu \mathrm{m} \pm 13,7$ до $197,4 \mu \mathrm{m} \pm 38,5$, в парафовеолярной - с $389,2 \mu \mathrm{m} \pm 13,4$ до $312,5 \mu \mathrm{m} \pm 25,3$. В перипапиллярной зоне - с $453,3 \mu \mathrm{m} \pm 21,9$ до $347,7 \mu \mathrm{m} \pm 61,8$. Исследовалась толщина нервных волокон в локусах максимальной толщины на расстоянии, в среднем, 200-220 $\mu$ от от фовеа. Под влиянием лечения при заднем увеите средняя толщина сенсорной части сетчатки в фовеолярной зоне уменьшилась с $357,5 \mu \mathrm{m} \pm 16,1$ до $252,1 \mu \mathrm{m} \pm 12,2$, в парафовеолярной - с 412,4 $\mu \mathrm{m} \pm 15,6$ до $377,4 \mu \mathrm{m} \pm 19,9$. В перипапиллярной зоне - с 489,4 $\mu \mathrm{m} \pm 76,2$ до 440,8 $\mu \mathrm{m} \pm 64,9$.

Морфометрические показатели по данным ОКТ в группе пациентов, получавших противовоспалительную и иммуносупрессивную терапию с электрофорезом Ципронекса ${ }^{\circledR}$ и Дексаметазона ВЗФ (срок наблюдения 3 месяца), представлены в табл. 3 .

Анализ данных, представленных в табл. 2, показал, что под влиянием лечения при переднем увеите средняя толщина сенсорной части сетчатки в 
Показатели средней остроты и полей зрения у больных увеитами до и после лечения (M $\pm \mathbf{m})$

\begin{tabular}{|c|c|c|c|c|}
\hline \multirow{2}{*}{ Исследования } & \multicolumn{2}{|c|}{ 1-я группа $(n=30$ глаз) } & \multicolumn{2}{|c|}{ 2-я группа (n=37 глаз) } \\
\cline { 2 - 5 } & до лечения & после лечения & до лечения & после лечения \\
\hline Острота зрения & $0,25 \pm 0,03$ & $0,5 \pm 0,02$ & $0,2 \pm 0,05$ & $0,75 \pm 0,02$ \\
\hline $\mathrm{p}$ & \multicolumn{2}{|c|}{$<0,02$} & \multicolumn{3}{c|}{$<0,02$} \\
\hline Суммарная величина полей зрения, град. & $450 \pm 1,8$ & $536 \pm 3,4$ & $453 \pm 2,1$ & $558 \pm 2,1$ \\
\hline $\mathrm{p}$ & \multicolumn{2}{|c|}{$<0,05$} & \multicolumn{3}{c}{$<0,05$} \\
\hline
\end{tabular}

Примечание:

p - уровень различий между показателями в сравниваемых группах

Таблица 2

Показатели толщины сенсорной части сетчатки в различных зонах глазного дна по данным ОКТ на фоне лечения у пациентов, получавших терапию без включения электрофореза (M $\pm \mathrm{SD})$

\begin{tabular}{|c|c|c|c|c|}
\hline \multirow{2}{*}{ Область исследования } & \multicolumn{2}{|c|}{ Толщзна сенсорной части сетчатки $(\mu \mathrm{m})$} & Толщина сенсорной части сетчатки $(\mu т)$ \\
\cline { 2 - 5 } & \multicolumn{2}{|c|}{ Передний увеит $(n=15)$} & \multicolumn{2}{|c|}{ Задний увеит $(n=15)$} \\
\cline { 2 - 5 } & $\begin{array}{c}\text { до } \\
\text { лечения }\end{array}$ & после лечения & дочения & после лечения \\
\hline Перипапиллярно & $453,3 \pm 21,9$ & $347,7 \pm 61,8$ & $489,4 \pm 76,2$ & $440,8 \pm 64,9$ \\
\hline Фовеола & $295,2 \pm 13,7$ & $197,4 \pm 38,5$ & $357,5 \pm 16,1$ & $252,1 \pm 12,2$ \\
\hline Парафовеолярно & $389,2 \pm 13,4$ & $312,5 \pm 5,3$ & $412,4 \pm 15,6$ & $377,4 \pm 19,9$ \\
\hline
\end{tabular}

Таблица 3

Показатели толщины сенсорной части и сосудистой оболочки сетчатки в различных зонах глазного дна по данным ОКТ на фоне лечения у пациентов, получавших терапию с включением электрофореза Ципронекса ${ }^{\circledR}$ и Дексаметазона ВФ3 (M \pm SD)

\begin{tabular}{|c|c|c|c|c|}
\hline \multirow{2}{*}{ Область исследования } & \multicolumn{2}{|c|}{ Толщина сенсорной части сетчатки $(\mu \mathrm{m})$} & Толщчна сенсорной части сетчатки $(\mu т)$ \\
\cline { 2 - 5 } & \multicolumn{2}{|c|}{ Передний увешт $(n=20)$} & \multicolumn{2}{|c|}{ Задний увеит $(n=17)$} \\
\cline { 2 - 5 } & $\begin{array}{c}\text { до } \\
\text { лечения }\end{array}$ & $\begin{array}{c}\text { по } \\
\text { лечения лечения }\end{array}$ & после лечения \\
\hline Перипапиллярно & $468,2 \pm 20,7$ & $324,1 \pm 35,2$ & $499,4 \pm 87,6$ & $420,1 \pm 46,4$ \\
\hline Фовеола & $298,7 \pm 18,4$ & $186,1 \pm 23,3$ & $376,1 \pm 12,4$ & $223,2 \pm 11,5$ \\
\hline Парафовеолярно & $398,3 \pm 11,2$ & $310,1 \pm 21,1$ & $432,4 \pm 25,3$ & $343,2 \pm 11,1$ \\
\hline
\end{tabular}

фовеолярной зоне уменьшилась с $298,7 \mu \mathrm{m} \pm 18,4$ до $186,1 \mu \mathrm{m} \pm 23,3$, в парафовеолярной - с $398,3 \mu \mathrm{m} \pm 11,2$ до $310,1 \mu \mathrm{m} \pm 21,1$. В перипапиллярной зоне - с $468,2 \mu \mathrm{m} \pm 20,7$ до $324,1 \mu \mathrm{m} \pm 35,2$. Под влиянием лечения при заднем увеите средняя толщина сенсорной части сетчатки в фовеолярной зоне уменьшилась с $376,1 \mu \mathrm{m} \pm 12,4$ до $223,2 \mu \mathrm{m} \pm 11,5$, в парафовеолярной с $432,4 \mu \mathrm{m} \pm 25,3$ до $343,2 \mu \mathrm{m} \pm 11,1$, в перипапиллярной зоне - с 499,4 $4 \mathrm{~m} \pm 87,6$ до $420,1 \mu \mathrm{m} \pm 46,4$.

Парафовеолярно толщина сетчатки во время воспаления в обеих группах увеличена на 23,4-55 \% $(\mathrm{p}=0,001)$, перипапиллярно - на 6-28 \% ( $\mathrm{p}=0,0001)$ за счет макулярного отека и нарушения архитектоники сетчатки вследствие экссудации, инфильтрации, а также начального рассасывания экссудата, формирования рубцовых изменений. При передних увеитах, после окончания сроков наблюдения в обеих группах больных, наблюдается истончение сенсорной части в перипапиллярной, парафовеолярной и фовеолярной зонах сетчатки. Уменьшение толщины сетчатки наи- более выражено в группе с применением электрофореза Ципронекса ${ }^{\circledR}$ и Дексаметазона ВФЗ в зоне фовеа - на 38,8-45,6 \% (p=0,0001), что клинически выражается в уменьшении кистозного и диффузного макулярного отека и повышении остроты зрения. При очаговом и диссеминированном хориоретините (заднем увеите) в период ремиссии показатели толщины сенсорной части сетчатки в области фовеа уменьшились на $38,5 \%(p=0,001)$, что связано с остатками диффузного отека, возникновением вторичного дистрофического процесса в сетчатке в результате воспаления. Значительной разницы между группами по количеству пациентов с положительной клинической динамикой не было. Клиническое улучшение наблюдалось в 86,6 \% (26 глаз) в группе системной терапии и в 91,8 \% (34 глаза) в группе с использованием помимо системной терапии електрофореза Ципронекса $®$ и Дексаметазона ВФ3 p=0,20. При переднем увеите это выражалось в рассасывании экссудата, преципитатов, уменьшении плавающих помутнений в стекловидном 
теле. При заднем увеите произошло рассасывание кровоизлияний, экссудата у очагов, резорбция очагов, а полная резорбция макулярного отека наблюдалась в $52 \%$ случаев в группе системной терапии и в $78 \%$ случаев в группе с применением электрофореза Ципронекса ${ }^{\circledR}$ и Дексаметазон ВФЗ, p=0,02.

Таким образом, в контроле динамики лечения передних и задних увеитов независимо от этиологии особую роль играет ОКТ, позволяя объективно анализировать состояние макулярной зоны, контролировать макулярный отек и, при необходимости, своевременно назначать профилактическую терапию. Использование в комплексном лечении электрофореза Ципронекса ${ }^{\circledR}$ и Дексаметазона ВФ3 у больных увеитами независимо от этиологии процесса способствует исчезновению признаков воспаления, стабилизации зрительных функций, повышению остроты зрения в 3,5 раза и расширению поля зрения. Подводя итог вышеизложенному, можно отметить, что улучшение состояния сетчатки и остроты зрения отмечалось более чем у двух третей пациентов, получавших системную терапию и электрофорез Ципронекса® и Дексаметазона ВФЗ. При этом физиотерапевтическое введение методом электрофореза Ципронекса® и Дексаметазона ВФЗ сопровождалось более выраженной резорбцией отека и уменьшением толщины сетчатки. К концу периода наблюдения улучшение состояния сетчатки и полная резорбция отека наблюдалась в 78 \% случаев. При передних увеитах после окончания сроков наблюдения в обеих группах больных наблюдалось истончение сенсорной части в перипапиллярной, парафовеолярной и фовеолярной зонах сетчатки. Уменьшение толщины сетчатки было наиболее выражено в группе с использованием электрофореза Ципронекса ${ }^{\circledR}$ и Дексаметазона ВФЗ в зоне фовеа - на 38,8-45,6 \% $(\mathrm{p}=0,0001)$, что клинически выражается в уменьшении кистозного и диффузного макулярного отека, и повышении остроты зрения. При очаговом и диссеминированном хориоретините (заднем увеите) в период ремиссии показатели толщины сенсорной части сетчатки в области фовеа уменьшились на $38,5 \%(p=0,001)$, что связано с остатками диффузного отека, а также возникновением вторичного дистрофического процесса в сетчатке в результате воспаления.

\section{Выводы}

1. Электрофорез Ципронекса ${ }^{\circledR}$ и Дексаметазона ВФЗ у больных увеитами независимо от этиологии процесса способствует исчезновению признаков воспаления, стабилизации зрительных функций, повышению остроты зрения в 3,5 раза и расширению поля зрения. Полная резорбция макулярного отека наблюдалась в 52 \% случаев в группе системной терапии и в 78 \% случаев в группе с применением электрофореза Ципронекса ${ }^{\circledR}$ и Дексаметазона ВФЗ, $\mathrm{p}=0,02$.

2. Электрофорез с применением Ципронекса ${ }^{\circledR}$ и Дексаметазона ВФЗ хорошо переносится больными и может быть использован в лечении увеитов независимо от этиологии.

\section{Литература}

1. Авдеева О. Н. Клиническое использование оптической когерентной томографии в оценке ультраструктурных изменений сетчатки на фоне комплексного лечения хориоретинитов различной этиологии / О. Н. Авдеева, Н. Г. Варнавская, М. Ю. Прокопьева // Материалы XVI науч.-практич. конф. офтальмологов. - Екатеринбург, 2008. - C. 7-9.

2. Гланц С. Медико-биологическая статистика / С. Гланц. - М.: Практика, 1998. - 459 с.

3. Иваницкая E. B. Оптическая когерентная томография в диагностике состояния макулярной области сетчатки / Е. В. Иваницкая // Офтальмол. журн. 2007. - № 5. - С. $71-73$.

4. Катаргина Л. А., Эндогенные увеиты у детей и подростков / Л. А. Катаргина, А. В. Хватова. - М.: Медицина, 2000. - 320 с.

5. Коновалова Н. В. Изучение состояния сенсорной части сетчатки и сосудистой оболочки глаза у больных увеитами по данным оптической когерентной томографии / Н. В. Коновалова, Н. И. Храменко, Шайби Абдеррахим [и др.] / Офтальмологический журнал. - 2014. - № 3. - С. 34-41.

6. Свирин A. B. Спектральная оптическая когерентная томография: принципы и возможности метода / А. В. Свирин, Ю. И. Кийко, Б. В. Обруч, А. В. Богомолов // Клинич. офтальмология. -2009. - Т. 10, № 2. - С. 50-53.

7. Щуко А. Г. Восьмилетний опыт использования оптической когерентной томографии в офтальмологии / А. Г. Щуко, А. С. Алпатов, С. И. Жукова // Вестник офтальмологии. - 2006. - № 3. - С. 34-36.

8. Alamouti B. Retinal thickness decreases with age: an OCT study / B. Alamouti, J. Funk // Brit. J. Ophthalmol. - 2003. - Vol. 87, № 7. - P. 899-901.

9. Atmaca L. Optical coherence tomography in inflammatory CMV / L. Atmaca, K. Sonmez // 10th International Ocular Inflammation Society (IOIS) Congress: abstract book. - Prague, 2009. - P. 16.

10. Tomkins-Netzer O. Outcome of treatment of uveitic macular edema. The multicenter uveitis steroid treatment trial: 2-year results / O. Tomkins-Netzer, S. Lightman, L. Drye [et al.] // Ophthalmology. - 2015. - Vol. 122. - P. 2351-2359. 


\title{
РОЛЬ ЕЛЕКТРОФОРЕЗУ ПРОТИЗАПАЛЬНИХ РЕЧОВИН У ЛІКУВАННІ УВЕЇТІВ
}

\section{Н. В. Коновалова, Н. І. Храменко, О. В. Іваницька, Т. М. Серебріна, А. В. Рибалко}

Соціальна значущість увеїтів обумовлена їхньою високою частотою, переважним ураженням осіб працездатного віку, а також високою частотою інвалідицації по зору внаслідок увеїтів. Останнім часом кількість даної патології значно збільшилася.

Мета роботи. Вивчення терапевтичної ефективності електрофорезу із застосуванням Ципронекса® та Дексаметазона ВФЗ у комплексній терапії хворих на увеїти (передні та задні).

Матеріали і методи. Під нашим наглядом знаходилися 67 пацієнтів (67 очей), рандомізованих на дві групи: 1-a група хворих (30 осіб) отримувала системну протизапальну, імуносупресивну терапію, а пацієнтам 2-ї гру$n u$ (37 осіб) був застосований трансорбітальний і ендоназальний електрофорез Ципронекса ${ }^{8}$ і Дексаметазона ВФЗ. Обстеження: визначення гостроти зору, поля зору, тонометрія, біомікроскопія, офтальмоскопія. Строк спостереження - 3 місяці.

Результати та їх обговорення. Отримані дані, які свідчать про ефективність використання в комплексному лікуванні увеїтів електрофорезу із застосуванням Ципронекса® і Дексаметазона ВФЗ незалежно від етіології процесу. Зменшення товщини сітківки найбільш виражене в групі з використанням електрофорезу із застосуванням Ципронекса ${ }^{\circledR}$ і Дексаметазона ВФЗ в зоні фовеа - на 38,8-45,6 \% (p=0,0001), що клінічно відображається в зменшенні макулярного набряку і підвищенні гостроти зору. При вогнищевому і дисемінованому хоріоретиніті (задньому увеїті) в період ремісії показники товщини сенсорної частини сітківки в зоні фовеа зменшилися на 38,5 \% (p=0,001), що зумовлено із залишками дифузного набряку, виникненням вторинного дистрофічного процесу в сітківці в результаті запалення. При передніх увеїтах після закінчення строків нагляду в обох групах хворих спостерігається витончення сенсорної частини в перипапілярній, парафовеолярній та фовеолярній зонах сітківки.

Висновки. 1.Електрофорез із застосуванням Ципронекса ${ }^{\circledR}$ i Дексаметазона ВФЗ у хворих на увеїти незалежно від етіології процесу сприяє зникненню ознак запалення, стабілізації зорових функцій, підвищенню гостроти зору в 3,5 разу і розширенню поля зору. 2. Електрофорез із застосуванням Ципронекса® і Дексаметазона ВФЗ добре переноситься хворими і може використовуватися в лікуванні увеїтів незалежно від їхньої етіології.

Ключові слова: увеїти, ОКТ, електрофорез, Ципронекс ${ }^{\circledR}$, Дексаметазон ВФЗ.

\section{ROLE OF ELECTROPHORESIS ANTI-INFLAMMATORY DRUGS IN THE TREATMENT OF UVEITIS}

\author{
N. V. Konovalova, N. I. Chramenko, O. V. Ivanitska, T. M. Serebrina, A. V. Rubalko
}

Institute of Eye Diseases and Tissue Therapy named after V. P. Filatov of the NAMS

\section{Odessa, Ukraine}

Introduction. The social significance of uveitis is determined by the high frequency of occurrence, primary affecting persons of working age, causing the high incidence of visual disability. Recently, the number of uveitis regardless of etiology has significantly increased. Based on the study of the role of electrophoresis of cipronex ${ }^{\circledR}$ and dexamethasone in the complex therapy of patients with uveitis in the treatment process, one can predict the course of the disease and the effectiveness of treatment.

Aim. The aim of this work is to study the activity role of electrophoresis of cipronex ${ }^{\circledR}$ and dexamethasone in the complex therapy of patients with uveitis.

Material and methods. There were 67 patients randomized into two groups with anterior and posterior uveitis etiology who were examined for ophthalmology (ophthalmoscopy, tonometry, visometry, OCT, visual field). The first group of 30 patients received anti-inflammatory therapy, and the second group of 37 patients were given electrophoresis of cypronex ${ }^{\circledR}$ and dexamethasone.

Results. The obtained data demonstrate the efficiency of the treatment with electrophoresis of cypronex ${ }^{\circledR}$ and dexamethasone. The decrease in the thickness of the retinal part by 35,8-45,6 percent is more pronounced in the second group, which indicates a decrease in the symptoms of inflammation and in macular edema. The thickness of the sensory part in the fovea region is decreased by a 38,5 percent, which is associated with a decrease in the symptoms of inflammation.

Conclusions. Electrophoresis of cipronex ${ }^{\circledR}$ and dexamethasone is an effective method of treatment, contributing to the increased visual acuity and the disappearance of inflammation.

Key words: uveitis, OCT, electrophoresis, cypronex ${ }^{\circledR}$, dexamethasone.

Стаття надійшла до редакції 03.04.2018 p. 